\title{
Back to basics with receptors and ligands - molecules, mechanisms and medicine
}

\author{
Selvanayagam Nirthanan ${ }^{1}$ \\ Journal of the Ceylon College of Physicians, 2019, 50, 51-63
}

\section{General introduction}

Drug discovery is a complex, substantially long, technology-driven, labour-intensive and inordinately expensive process involving target discovery and validation, lead identification by high-throughput screening, and lead optimization by medicinal chemistry, preclinical evaluation in animal models, pharmacological screening (ADME screen: administration, distribution, metabolism, elimination) and studies of toxicology, specificity, and drug interactions $\mathbf{s}^{1,2}$. While comprehensive drug discovery workflows are predominantly undertaken in the big pharma domain, drug discovery in academia must not be discounted. Research relevant to drug discovery in academia is generally at the fundamental level, with a focus on drug mechanisms and the identification and validation of potential therapeutic targets, often in commercially unattractive, but relevant therapeutic areas particularly for the developing world, including rare disorders, parasitic diseases, and in research into natural products ${ }^{3,4}$. Investigating natural sources for drug leads include compounds from venomous animals; with illustrious examples of success such as captopril (angiotensin converting enzyme inhibitor for the treatment of hypertension), exenatide (a glucagonlike peptide- 1 receptor agonist for the treatment of type 2 diabetes) and ziconotide (an $\mathrm{N}$-type calcium channel blocker for intractable pain) $)^{5,6}$.

Drug discovery in academia is usually associated with identification of drug targets and mechanisms, often with the overarching goal of progressing to proof-of-concept studies and translational research with commercial viability - the so-called 'bench to bedside' vision. Nevertheless, outcomes such as development of probe molecules that can serve as research or diagnostics tools to dissect molecular mechanisms or pathophysiological pathways, or contribution to the structural and functional characterization of receptors, ion channels, enzymes and other molecular targets are also critical for drug discovery ${ }^{2,7}$.

This oration paper outlines an overview of two decades of research in the academia, focusing on the neurotransmitter-gated family of ion channel receptors, specifically the nicotinic acetylcholine receptor (nAChR); investigating both, novel ligands and drugs for the receptor, as well as characterizing their binding sites within the receptor. Collectively, these studies have made substantial contributions of clinical, pharmacological and neurobiological significance.

\section{Methods}

\subsection{Experimental procedures for identification of drug binding sites within nicotinic acetylcholine} receptors

Membranes rich in nAChRs were isolated from Torpedo californica (Pacific electric ray) electric organs as described previously ${ }^{8}$. Photo-reactive derivatives of the general anaesthetic drug etomidate were chemically synthesized ${ }^{9-11}$ and their effects on the equilibrium binding of tritium $\left.\left({ }^{3} \mathrm{H}\right]\right)$ labelled acetylcholine or non-competitive nAChR antagonists, $\left[{ }^{3} \mathrm{H}\right]$ tetracaine, or $\left.{ }^{3} \mathrm{H}\right]$ phencyclidine, to $\mathrm{nAChR}$-rich membranes were studied using radioligand binding assays ${ }^{12-14}$. Two-electrode voltage clamp (TEVC) electrophysiology was used to study the effects of etomidate derivatives on Torpedo $\alpha_{2} \beta \gamma \delta$ nAChRs expressed in Xenopus oocytes ${ }^{10,12}$. Photolabelling of $\mathrm{nAChRs}$

\footnotetext{
${ }^{1}$ School of Medical Science and School of Medicine, Griffith Health Group, Gold Coast Campus, Griffith University, Queensland, Australia.
}

Correspondence: S N, e-mail: niru.nirthanan@griffith.edu.au

This is an open-access article distributed under the terms of the Creative Commons Attribution License, which permits unrestricted use, distribution, and reproduction in any medium, provided the original author and source are credited. 
with photo-reactive drugs was carried out as described ${ }^{10,11,14}$. In brief, nAChR-rich Torpedo membranes were incubated with $\left[{ }^{3} \mathrm{H}\right]$-labelled photo-reactive etomidate, irradiated for $30 \mathrm{~min}$ at $360 \mathrm{~nm}$ and the photolabelled membranes were solubilized and separated by SDS-polyacrylamide gel electrophoresis into nAChR $\alpha, \beta, \gamma$, and $\delta$ subunits. The incorporation of ${ }^{3} \mathrm{H}$ into individual $\mathrm{nAChR}$ subunits was quantified by liquid scintillation counting of excised gel slices containing the polypeptide bands of the nAChR subunits. The gel bands containing the $\alpha$, $\beta, \gamma$, and $\delta$ subunits were passively eluted and the proteins digested with proteolytic enzymes. The digests of the $\mathrm{nAChR} \alpha, \beta, \gamma$, and $\delta$ subunit proteins were fractionated and retrieved by reverse-phase HPLC. Amino acid sequencing was performed on each peptide fragment and the product of each amino acid cycle was collected for scintillation counting to determine the specific amino acid(s) into which there was incorporation of ${ }^{3} \mathrm{H}$, representing photolabelling by the drug. Based on the data generated, a homology model of the Torpedo californica nAChR was constructed using the Accelerys Discovery Studio software to visualise the binding of the drug within the nAChR.

\subsection{Experimental procedures for the isolation, purification, characterisation and structure-function analyses of novel scorpion toxins}

Studies on novel toxins from the Malaysian black scorpion (Heterometrus spinifer) utilized venom extracted from scorpions housed at the National University of Singapore. Pooled scorpion venom was subjected to ultrafiltration, and the ultrafiltrate of $\mathrm{Mr}<5000$ subjected to a single-step, reverse-phase HPLC to isolate and purify novel toxins to homogeneity, as verified by capillary electrophoresis as well as analytical HPLC ${ }^{15,16}$. The molecular masses of the purified scorpion toxins were determined by electrospray ionization mass-spectrometry (ESI-MS) or matrix-assisted laser desorption ionization-time of flight mass-spectrometry (MALDI-TOF-MS). Amino terminal sequencing of novel scorpion toxins was done by automated Edman degradation. Given the very low yield of the native toxin in venom, synthetic analogues of the scorpion toxins were synthesized using solid phase methodology with Fmoc chemistry ${ }^{16,17}$. Molecular modelling was carried out using the program MODELER in the Accelrys Discovery Studio software to determine the predicted structure of toxins ${ }^{16,17}$. TEVC electrophysiological studies determined the pharmacological actions of scorpion toxins on voltage-gated ion channels ${ }^{16,18,19}$.

\subsection{Experimental procedures for the isolation, purification, characterisation and structure-function analyses of novel snake toxins}

The isolation and purification of peptide toxins from snake venoms is a well-established, widely utilized and streamlined protocol in our laboratory ${ }^{20-23}$. Briefly, commercially purchased lyophilised snake venom was subjected to multi-stage high performance liquid chromatography (HPLC) - firstly, separation of venom based on the molecular weight of the components, followed by separation of selected protein fractions based on the hydrophobicity of proteins using reverse-phase HPLC. The molecular mass and homogeneity of snake toxins were determined as described above. The structural characterization of novel snake toxins, from primary to quaternary protein structure, was carried out as previously described ${ }^{22-25}$, with the amino acid sequence determined by the Edman degradation and the three-dimensional structures determined by $\mathrm{x}$-ray crystallography ${ }^{22,23}$ or nuclear magnetic resonance $(\mathrm{NMR})^{26,27}$. The pharmacological characterisation of novel snake toxins was carried out in vitro, on isolated tissues in organ bath studies as well as in vivo, in anaesthetised rodents employing widely utilised pharmacological techniques in our laboratory $20,21,28,29$ and nerve-skeletal muscle preparations that are representative models of the avian and mammalian neuromuscular junctions ${ }^{30,31}$. The pharmacological effects of snake toxins on the contractile responses of the isolated muscle were then investigated to provide a quantitative measure of neurotoxicity and recovery of the muscle from complete neuromuscular blockade was also evaluated ${ }^{29}$. TEVC electrophysiological studies were utilised to identify the specific molecular target(s) of the novel snake toxins ${ }^{20,22,23,29}$.

\subsection{Ethical considerations}

All animal studies were in compliance with the National University of Singapore's and Harvard Medical School's Institutional Animal Care and Use Committee Regulations and the Griffith University Animal Ethics Guidelines (Australia), which conform to the World Health Organization's International Guiding Principles for Animal Research ${ }^{32}$. 


\section{Results and discussion}

3.1 Drug discovery in academia: identification and characterization of drug binding sites within the nicotinic acetylcholine receptor

The excitatory nAChR is a member of the superfamily of neurotransmitter-gated ion channels that also includes the inhibitory $G A B A_{A}$ receptors $\left(G A B A_{A} R s\right)$. GABA $A_{A} R s$ and $n A C h R s$ are primary molecular targets of drugs widely used in general anaesthesia, psychiatry, neurodegeneration and neurology as well as substances of abuse ${ }^{33-35}$; which elicit their actions by acting as agonists, competitive antagonists, non-competitive antagonists and /or positive allosteric modulators ${ }^{33,35-37}$. The $n A C h R s$ and GABA $_{A}$ Rs are composed of five homologous subunits, each with a large amino-terminal extracellular domain where neurotransmitter binding sites are located at subunit interfaces, and a transmembrane domain (TMD) consisting of four $\alpha$-helices (M1-M4) which associate around a central, selective, ion channel ${ }^{38,39}$. Within the $\mathrm{nAChR}$ TMD, amino acids from each M2-helix contribute to the lumen of the channel, which constitutes the binding site of many nAChR non-competitive inhibitors ${ }^{10}$, and there are also pockets within each subunit helix bundle and at subunit interfaces that are potential binding sites for allosteric modulators ${ }^{40}$.

Positive allosteric modulators of agonist binding represent an important class of therapeutic agents, which enhance the efficacy of endogenous neuro-transmitter signalling while avoiding the prolonged, non-physiological pattern of receptor activation produced by agonists ${ }^{41-44}$. Without reliable structural data pertaining to the receptor, in particular the specific sites for drug binding and interaction, the mechanistic basis for pharmacological modulation of $n A C h R s$ and $G_{A B A} R s$ remains largely unknown ${ }^{36}$.

\subsubsection{Identification of the binding site for the general anaesthetic drug, etomidate, within the nicotinic acetylcholine receptor}

To identify the binding sites in a ligand-gated ion channel for etomidate, an intravenous general anaesthetic, nAChR-rich membranes were photolabelled with a photoactivatable analogue, $\left[{ }^{3} \mathrm{H}\right]$ azietomidate ${ }^{10}$. In radio-ligand binding assays, both etomidate and azietomidate acted as a non-competitive inhibitor of the nAChR since they inhibited the binding of the non-competitive antagonist $\left[{ }^{3} \mathrm{H}\right]$ phencyclidine, which is known to bind inside the ion channel. Furthermore, azietomidate and etomidate bind with 10-fold higher affinity to nAChRs in the desensitized state $\left(\mathrm{IC}_{50}=70 \mu \mathrm{M}\right)$ than in the closed channel state. nAChR-rich membranes were photolabelled with $\left[{ }^{3} \mathrm{H}\right]$ azietomidate, which showed preferential photo-incorporation of $\left[{ }^{3} \mathrm{H}\right]$ azietomidate into the $\alpha$ and $\delta$ subunits of the nAChR. Specifically, the labelled amino acids were identified by Edman degradation to be $\alpha \mathrm{Glu}-262$ and $\delta G \mathrm{In}-276$ at the extracellular end and $\delta$ Ser-258 and $\delta$ Ser-262 toward the cytoplasmic end of the nAChR ion channel (see Figure 1). These studies revealed the primary binding site for azietomidate, and hence, likely for etomidate, to be within the ion channel of the $\mathrm{nAChR}^{10}$.

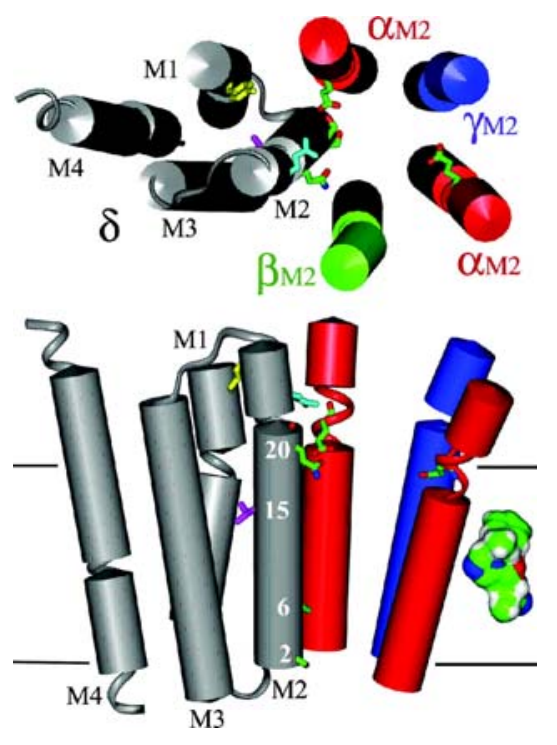

Figure 1. Binding site in the nicotinic acetylcholine receptor for azietomidate, a photoreactive analogue of the general anaesthetic etomidate. The location of amino acids in the $\mathrm{nAChR}$ ion channel photolabelled by $\left[{ }^{3} \mathrm{H}\right]$ azietomidate is shown in this tube and ribbon representation of the $\mathrm{nAChR}$ $\delta$ subunit transmembrane domain and the $M 2 \alpha$-helices of the other subunits that form the lumen of the ion channel are shown, as viewed from the extracellular domain (top panel) and in cross-section (bottom panel, extracellular surface up).

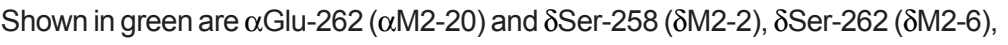
and $\delta \mathrm{Gln}-276(\alpha \mathrm{M} 2-20)$, which are labelled by azietomidate. Shown in magenta is $\alpha \mathrm{M} 2-15$, a position in the $\mathrm{GABA}_{\mathrm{A}} \mathrm{R} \delta$ subunit identified as an etomidate affinity determinant. Shown in yellow is $\delta T y r-228$, in $\delta M 1$, which is labelled by $\left[{ }^{14} \mathrm{C}\right]$ halothane. Azietomidate, which measures $13 \AA$ in an extended conformation, is shown in a space-filling representation for comparison of dimensions (to the right in the bottom panel). 


\subsubsection{Identification of binding sites for positive allosteric modulators within the nicotinic acetylcholine receptor}

TDBzl-etomidate (4-[3-(trifluoromethyl)-3H-diazirin-3-yl]benzyl-1-(1-phenylethyl)-1H-imidazole-5-carboxylate), an analogue of the general anaesthetic, etomidate, was chemically synthesized ${ }^{9}$. Interestingly, in electrophysiological studies, TDBzl-etomidate acted as a positive allosteric nAChR modulator, rather than an inhibitor like etomidate ${ }^{12}$. TDBzl-etomidate $(>10 \mu \mathrm{M})$ increased the submaximal response of nAChRs to acetylcholine in a concentration-dependent manner, with a 2.5 -fold increase seen at $60 \mu \mathrm{M}$. At higher concentrations, TDBzl-etomidate inhibited the binding of non-competitive nAChR antagonists $\left[{ }^{3} \mathrm{H}\right]$ tetracaine and $\left[{ }^{3} \mathrm{H}\right]$ phencyclidine $\left(\mathrm{IC}_{50}=0.8 \mathrm{mM}\right)$.

nAChR-rich membranes were photolabelled with [ $\left.{ }^{3} \mathrm{H}\right] \mathrm{TDBz}$-etomidate, and the labelled amino acids identified by Edman degradation ${ }^{11}$ to be in the ion channel at positions M2-9 ( $\delta$ Leu-265), M2-13 ( $\alpha$ Val-255, $\alpha$ Val-269), and M2-10 ( $\alpha$ Ser-252). In addition, there was labelling in $\delta M 3$ ( $\gamma$ Met-299), but not in M3, and labelling at the lipid interface ( $\alpha$ Cys-412 and $\alpha$ Met-415). These data reveal that TDBzl-etomidate binds at two distinct sites - within the lumen of the ion channel (labelling of M2-9 and 13), an inhibitory site for NAChR; and at the interface between the and subunits (labelling of $\alpha \mathrm{M} 2-10$ and Met-299), likely to be a site for positive allosteric modulation of nAChRs (see Figure 2). This was the first report of the detailed characterization of a positive allosteric site within nAChRs, with implications for drug design for diseases underpinned by impaired cholinergic function (e.g. Alzheimer's disease).

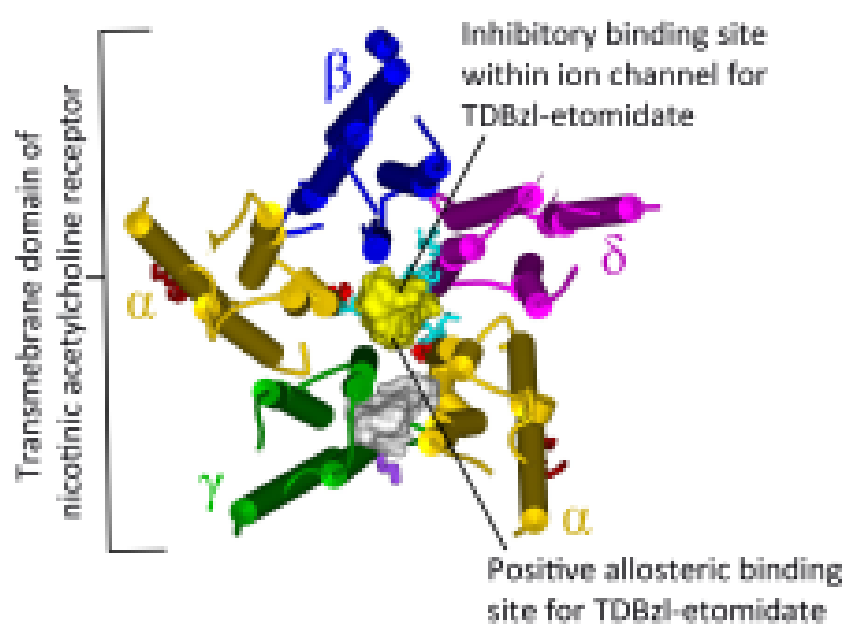

Figure 2. Binding sites in the nicotinic acetylcholine receptor for the positive allosteric modulator (TDBzletomidate). Three-dimensional structural model of the of the transmembrane domain of the Torpedo californica nicotinic acetylcholine receptor (subunits $\alpha$, gold; $\beta$, blue; $\gamma$, green; $\delta$, magenta) from perspective of looking down into the ion channel from the extracellular side. Amino acid residues photo-labelled by [ $\left.{ }^{3} \mathrm{H}\right]$ TDBzl-etomidate are shown in stick format, color-coded

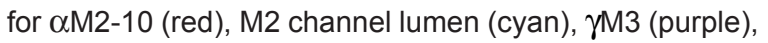
and $\alpha \mathrm{M} 4$ (brown). The binding site for TDBzl-etomidate within the ion channel lumen (inhibitory site; occupied at high concentrations) is shown in yellow; or in a novel binding pocket between the $\gamma$ and $\alpha$ subunits (positive allosteric site; occupied at low concentrations) are shown in Connolly surface representations.

\subsubsection{Identification of binding sites for partial agonists in the nicotinic acetylcholine receptor}

APFBz-choline (4-azido-2,3,5,6-tetrafluorobenzoylcholine), a photoreactive analogue of benzoylcholine, a partial agonist of nAChRs, was synthesised and its pharmacology and binding site within the nAChR deciphered using electrophysiology and photo-labelling ${ }^{11}$. In TEVC experiments, APFBz-choline acted as a low-efficacy partial agonist, eliciting maximal responses that were $0.3-0.1 \%$ of that of acetylcholine for $n A C h R s$. Equilibrium binding studies of $\left.{ }^{3} \mathrm{H}\right] \mathrm{APFBz}-\mathrm{choline}$ with nAChRs revealed that it bound to the acetylcholine-binding site (affinity of Keq $=12 \mu \mathrm{M}$ ). Photolabelling experiments further supported the binding of APFBz-choline to the acetylcholinebinding site of the receptor, since incorporation of [3H]APFBz-choline into the nAChR was inhibited in the presence of an agonist. Photolabelled amino acids in the agonist binding sites were identified to be $\gamma$ Leu-109/ $\delta$ Leu-111, $\gamma \mathrm{Tyr}-111$, and $\gamma \mathrm{Tyr}-117$ in binding site segment $\mathrm{E}$ as well as $\alpha \mathrm{Tyr}-198$ in $\alpha$ subunit binding site segment $C$ of the acetylcholine-binding site (see Figure 3$)^{11}$. Insight into partial agonist binding within nAChRs in the context of its pharmacology is useful for new therapeutic interventions, such as for nicotine addiction and cognitive decline $e^{45,46}$. 


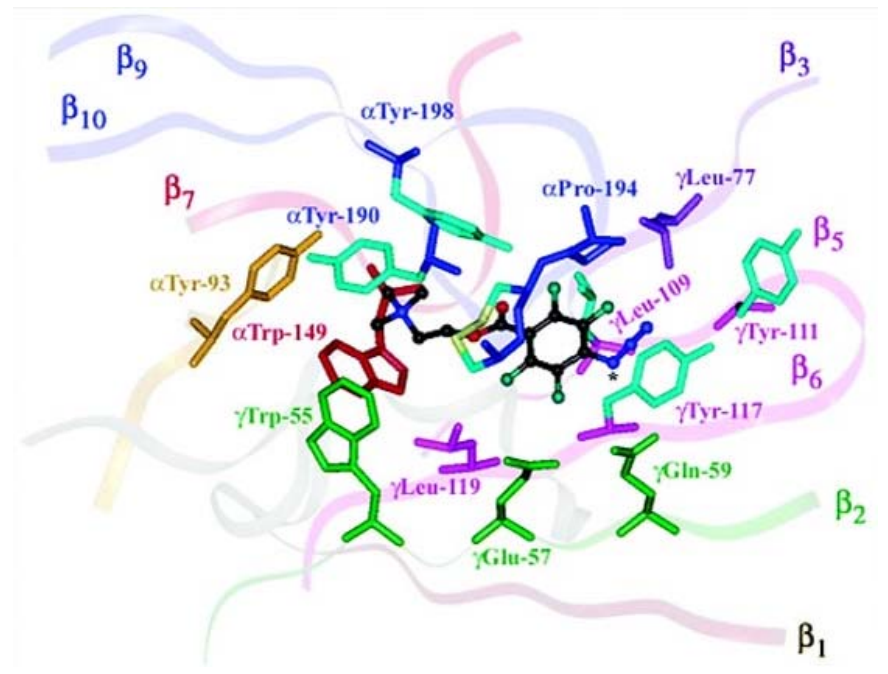

Figure 3. Binding site for the partial agonist APFBzcholine in the nicotinic acetylcholine receptor. Threedimensional structural model of the extracellular region of the Torpedo californica nicotinic acetylcholine receptor showing the binding site for APFBz-choline, located within the acetylcholine (agonist) binding site located at the $\alpha-\gamma$ subunit interface. APFBz-choline is shown as a ball-andstick structure with atom types coloured as follows: black for carbon, blue for nitrogen, red for oxygen, and teal for fluorine. The amino acid residues of the receptor contributing to the binding of APFBz-choline are shown in stick representation with their colours corresponding to the different agonist site segments (ribbons): segment $A$ in gold, segment $B$ in red, segment $C$ in blue, segment $D$ in green, and segment $E$ in magenta.

\subsection{Drug discovery in academia: discovery of novel lead molecules from scorpion venoms}

Voltage-gated potassium $\left(\mathrm{K}^{+}\right)$ion channels are present in a wide variety of cells and play a key role in electrical excitability, cell proliferation, apoptosis, and volume regulation ${ }^{47,48}$. Of clinical interest is the demonstration that Kv1.3 channels are widely expressed by the autoreactive memory T lymphocytes, believed to be associated with autoimmunity; suggesting that Kv1.3 channels maybe valid targets for diagnoses and treatment of autoimmune disorders ${ }^{48,49}$. Furthermore, Kv1.3 channels have also been considered as a potential molecular target for the diagnostics and therapy of some cancers ${ }^{50}$. A multitude of scorpion toxins targeting $\mathrm{K}^{+}$channels, with diverse pharmacological selectivity for various $\mathrm{K}^{+}$channels have been characterized ${ }^{51,52}$. These toxins typically consist of 23-43 amino acid residues and are classified into four subfamilies, of which $\alpha-K T x$ is the largest subfamily that shares a common cysteine-stabilized $\alpha / \beta$ motif53. Given the high specificity and affinity of scorpion toxins for $\mathrm{K}^{+}$ and other ion channels, their potential as lead candidates for drug discovery for ion channelopathies has been widely recognized ${ }^{5,52,54}$.

\subsubsection{Refining the structural determinants of peptide toxins for interacting with voltage-gated potassium channels}

A new family of $\mathrm{K}^{+}$channel toxins (designated $\mathrm{K}-\mathrm{KT} \mathrm{T}$ ) with a novel "xbi-helical" protein scaffold was discovered from the Indian black scorpion Heterometrus fulvipes venom in our laboratory ${ }^{55,56}$. $\kappa$-Hefutoxin-1 (K-KTx1.1), the first example of this family, had a protein structure that included amino acids $\mathrm{Y} 5$ and $\mathrm{K} 19$, considered to be the minimum functional dyad required for peptide toxins to bind and block $\mathrm{K}^{+}$channels ${ }^{17,57}$. Accordingly, $\kappa$-hefutoxin-1 was investigated and found to block Kv1.2 $\left(\mathrm{IC}_{50} \sim 40 \mu \mathrm{M}\right)$ and $\mathrm{Kv1} .3\left(\mathrm{IC}_{50} \sim 150 \mu \mathrm{M}\right)$ channels $^{55}$.

Subsequently, $\kappa-\mathrm{K} T \times 1.3$, a scorpion toxin that shares $\sim 60 \%$ identity with $\kappa$-hefutoxin 1 , was isolated from the Malaysian black scorpion $H$. spinifer venom ${ }^{15,16}$. Interestingly, despite the presence of the functional dyad (Y5 and K19), $\kappa-K T x 1.3$ failed to reproduce the $\mathrm{K}^{+}$channel blocking activity of $\kappa$-hefutoxin-1. Since the dyad lysine in $\kappa-K T \times 1.3$ was flanked by another lysine (K20) (see Figure 4), it was hypothesized that this additional positive charge could hinder the critical electrostatic interactions known to occur between the dyad lysine (K19) and the $\mathrm{K}^{+}$channel selectivity filter. Hence, mutants of $\kappa-K T \times 1.3$, substituting $\mathrm{K} 20$ with a neutral (K20A) or a negatively charged (K20E) amino acid were synthesized. $\mathrm{K}-\mathrm{KT}$ T1.3 K20E, in congruence with $\kappa$-hefutoxin 1, produced blockade of Kv1.2 $(\mathrm{IC} 50=37 \mu \mathrm{M})$ and $\mathrm{Kv} 1.3\left(\mathrm{IC}_{50}=54 \mu \mathrm{M}\right)$ but not Kv1.1 channels. $\kappa-\mathrm{KT} 1.3 \mathrm{~K} 20 \mathrm{~A}$ produced blockade of both $\mathrm{Kv} 1.2\left(\mathrm{IC}_{50}=37 \mu \mathrm{M}\right)$ and $\mathrm{Kv1} .3\left(\mathrm{IC}_{50}=116 \mu \mathrm{M}\right)$ and in addition, acquired affinity for $\mathrm{Kv} 1.1$ channels $\left(I_{50}=111 \mu \mathrm{M}\right)$. These data suggest that the presence of an additional charged residue in a position adjacent to the dyad lysine impedes the functional block of Kv1 channels produced by $\kappa-K T \times 1.3$, and may determine selectivity for peptide toxins for $\mathrm{K}+$ channel subtypes ${ }^{16}$. This work exemplifies the rationale and strategy for assigning a distinct pharmacological action to an otherwise inert toxin, highlighting the importance of the amino acids surrounding the putative functional site of a peptide. 


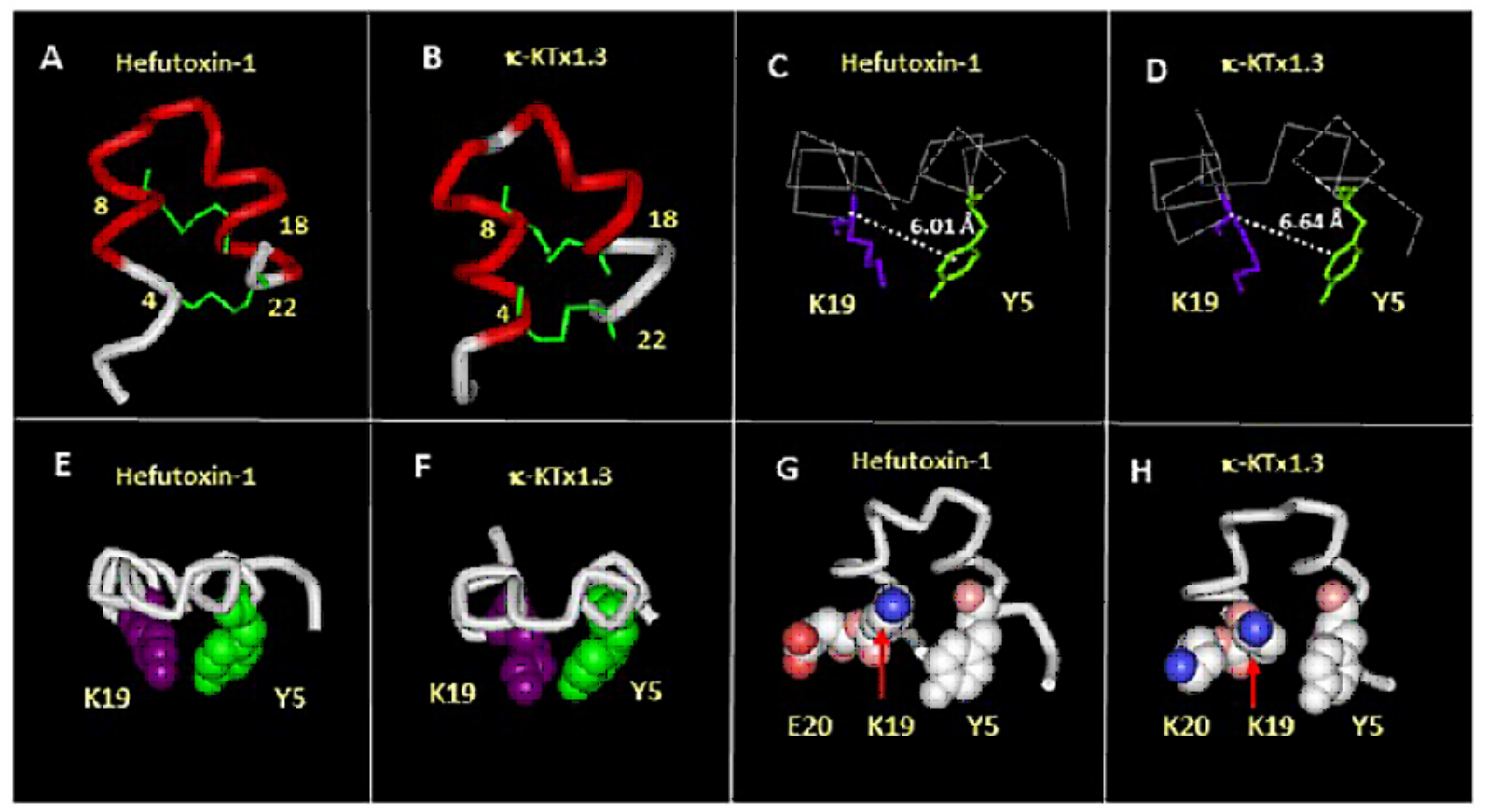

Figure 4. Comparison of the tertiary structures of $\mathrm{K}$-KTx 1.1 ( $\kappa$-hefutoxin) and pharmacology inert homologue K-KTx 1.3. (Panels A-B) Comparison of the tertiary structures of $K-K T \times 1.3$ and $\kappa$-hefutoxin 1 showing a compact structure consisting of two parallel $\alpha$-helices that are held together by the two disulfide bridges (C4-C22 and C8-C18) (shown in green). (Panels C-D) The potassium channel blocking activity of $\kappa$-hefutoxin 1 was deduced based on the presence of the functional dyad, $\mathrm{Y} 5$ and K19, positioned at a distance of $6.01 \AA$ between the $\alpha$-carbon of the lysine and the center of the aromatic face of the tyrosine (C). K-KTX1.3 also showed the presence of this dyad $(\mathrm{Y} 5, \mathrm{~K} 19)$ positioned at a distance of $6.64 \AA$ (D). The $\alpha$-carbon backbone structure is presented. (Panels E-F) In both, K-hefutoxin $1(\mathrm{E})$ and $\mathrm{K}-\mathrm{KTX} 1.3(\mathrm{~F})$, the dyad residues (shown in CoreyPauling-Koltun presentation) K19 (violet) and Y5 (green) protrude out of a flat surface formed by the edges of the two parallel $\alpha$-helices, in conformity with the general architecture of other pore-blocking potassium channel toxins. (Panels G-H) The amino acid residue at position 20, Glu20 in $\kappa$-hefutoxin $1(\mathrm{G})$ and Lys20 in K-KTX1.3 $(\mathrm{H})$ is also shown in relation to the functional dyad $(K 19, Y 5)$ in the respective toxins. $\ln (G)$ and $(H)$, both toxins are shown in similar orientations along the long-axis of the side chain of K19 with the selected residues in Corey-Pauling-Koltun representation. The amino acid residues are coloured according to their charge, with blue and red depicting positive and negative charge, respectively.

\subsubsection{Delineating structure-function relationships of a novel scorpion toxin}

Spinoxin, a 34-amino acid neurotoxin, was isolated from the Malaysian black scorpion Heterometrus spinifer venom, sequenced, and chemically synthesized ${ }^{58}$. Spinoxin ( $\left.\alpha-K T \times 6.13\right)$, was a potent inhibitor of voltage-gated $\mathrm{Kv1} .2\left(\mathrm{IC}_{50}=2.5 \mathrm{nM}\right)$ and $\mathrm{Kv} 1.3\left(\mathrm{IC}_{50}=63 \mathrm{nM}\right) \mathrm{K}^{+}$channels $^{18,19}$. Spinoxin has four conventionally paired disulfide bridges, like other $\alpha-K T \times 6$ subfamily members that share $50-65 \%$ sequence similarity with it. Molecular modelling of spinoxin revealed a compact molecule with a cysteine-stabilized $\alpha / \beta$-fold, typical of scorpion toxins that target $\mathrm{K}^{+}$channels ${ }^{18}$.

Utilising the "alanine scanning" approach, 25 analogues of spinoxin were chemically synthesised and the role of each amino acid in the toxin analysed for delineating the active site of the toxin ${ }^{18}$. Alanine replacements at Lys23, Asn26, and Lys30 resulted in loss of activity against Kv1.3 channels, with Lys23 appearing to be the key residue that underpins Kv1.3 channel inhibition. To investigate the role of the individual disulfide bonds in the structure-activity relationship of spinoxin, four analogues in which each pair of cysteine residues was replaced by 
alanine residues were synthesised. These studies concluded that three of the disulfide bridges (Cys1-Cys5, Cys2-Cys6, and Cys3-Cys7) were critical for structural stability and function, but interestingly, the analogue lacking Cys4-Cys8 retained both native secondary structure and inhibitory activity on Kv1.3 channels ${ }^{19}$.

\subsection{Drug discovery in academia: discovery of novel lead molecules from snake venoms}

The identification and characterization of the first neurotransmitter protein, the nAChR, was a significant milestone in molecular pharmacology; which was made possible only with the concurrent discovery of $\alpha$-bungarotoxin, the prototypical snake neurotoxin antagonist of the receptor ${ }^{59}$. Toxins from venomous animals including snakes have evolved to target various nAChR subtypes with cruise missile-like precision. Three-finger $\alpha$-neurotoxins ( $\alpha$-3FNTxs), which have a characteristic protein fold consisting of three finger-like $\beta$-stranded loops converging at a disulfide-rich hydrophobic core, constitute one of the largest families of snake toxins that produce neurotoxicity during envenomation ${ }^{60,61}$.

$\alpha-3 F N T x s$ are classified into short-chain (60-62 amino acid residues with four disulfide bonds) and long-chain (66-75 amino acid residues with five disulfide bonds) subfamilies. Both bind with high affinity (Kd $\sim 10-{ }^{10}-10-{ }^{11} \mathrm{M}$ ) to muscle $\alpha 1 \beta 1 \gamma \delta \mathrm{nAChRs}$, whereas long-chain, but not short-chain $\alpha-3 \mathrm{FNTxs}$, are capable of binding with high affinity $\left(\mathrm{K}_{\mathrm{d}}=10-{ }^{8}\right.$ to $\left.10-{ }^{9} \mathrm{M}\right)$ to neuronal $\alpha 7, \alpha 9$ and $\alpha 9 / \alpha 10 \mathrm{nAChRs}{ }^{60-62}$. Although the interactions of most $\alpha-3 F N T x s$ with nAChRs are effectively irreversible, novel $\alpha-3 F N T x s$ that produced rapid and complete reversible blockade of muscle nAChRs have been described, including candoxin from the Malayan krait Bungarus candidus, which belongs to a new 'non-conventional' class of $\alpha-3 F N T x{ }^{29,63}$. The primary challenge to developing nicotinic acetylcholine receptor-targeted therapeutics is the lack of selective ligands as investigative tools or drug leads, and in this context, the discovery of new snake toxins with novel pharmacology is paramount $34,46,64$.

\subsubsection{Dimerization of snake neurotoxins as a strategy to broaden the scope of selectivity for nicotinic acetylcholine receptor targets}

Although most $\alpha$-3FNTxs are monomers, a small number exist as dimers ${ }^{60,61}$. $\kappa$-Bungarotoxin is a homodimer composed of two non-covalently bound identical long-chain $\alpha-3 F N T x s$, which binds with high affinity to $\alpha 3 \beta 2$ $\left(\mathrm{IC}_{50}=3 \mathrm{nM}\right)$, but not to muscle $(\alpha 1 \beta 1 \gamma \delta) \mathrm{nAChRs}^{65}$. We described haditoxin isolated from King cobra Ophiophagus hannah venom that was a non-covalent homodimer composed of short-chain $\alpha$-3FNTxs, which inhibited muscle $(\alpha 1 \beta 1 \gamma \delta)\left(\mathrm{IC}_{50}=0.5 \mu \mathrm{M}\right)$ as well as neuronal $\alpha 7, \alpha 3 \beta 2$ and $\alpha 4 \beta 2 \mathrm{nAChRs}\left(\mathrm{IC}_{50}=0.5-2.5 \mu \mathrm{M}\right)^{23}$. We have also characterized the first heterodimeric $\alpha-3 F N T x$, irditoxin (from brown tree snake Boiga irregularis venom), in which the subunits are covalently-linked by a single intermolecular disulfide bridge, that exhibits potent $\left(\mathrm{IC}_{50}=10 \mathrm{nM}\right)$ taxa-specific neurotoxicity for avian $\alpha 1 \beta 1 \gamma \delta \mathrm{nAChRs}{ }^{22}$.

Recently, we detailed the pharmacological and structural characterization fulditoxin, from American coral snake (Micrurus fulvius fulvius) venom ${ }^{66}$. Fulditoxin's crystal structure revealed a non-covalent homodimer of two short-chain $\alpha$-3FNTxs, which, interestingly, produced potent neuromuscular blockade in avian skeletal muscle $\left(\mathrm{IC}_{50}=20 \mathrm{nM}\right)$, which was completely reversible, unlike that produced by typical snake $\alpha-3 \mathrm{FNTxs}$. Furthermore, fulditoxin produced blockade of human muscle $\alpha 1 \beta 1 \gamma \delta\left(\mathrm{IC}_{50}=2.5 \mu \mathrm{M}\right)$ as well as neuronal $\alpha 7\left(\mathrm{IC}_{50}=7 \mu \mathrm{M}\right)$, h $\alpha 4 \beta 2$ $\left(\mathrm{IC}_{50}=1.8 \mu \mathrm{M}\right)$ and h $\alpha 3 \beta 2\left(\mathrm{IC}_{50}=12 \mu \mathrm{M}\right)$ receptors, revealing a breadth of $\mathrm{nAChR}$ selectivity, which is unusual for short-chain $\alpha-3 F N T x s$ that target only muscle $n A C h R s^{67}$.

Therefore, dimeric $\alpha-3 F N T x s$ represent a structurally heterogeneous group of unique snake toxins (see Figure 5) exhibiting different receptor specificities from that expected for their monomeric components. Thus, dimerization presents novel structural conformations for $\alpha-3 F N T x$ s to enable interactions with new targets, diversifying the biological activity of snake venom. This opens significant opportunities for identifying new drug targets and the design of research and diagnostic tools as well as therapeutic agents. 


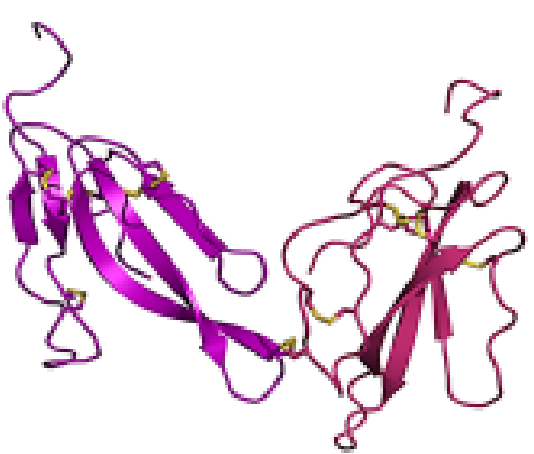

Irditoxin

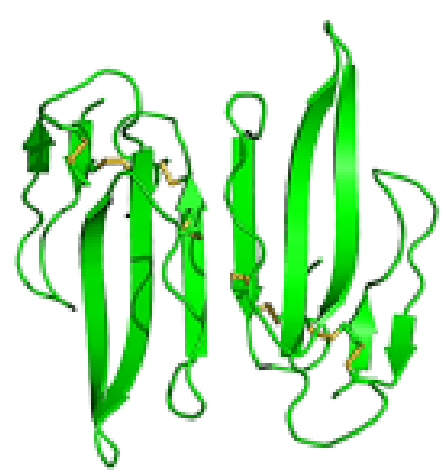

Haditoxin

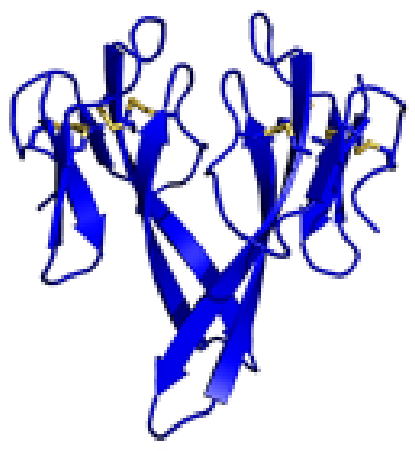

Fulditoxin

Figure 5. Dimeric three-finger neurotoxins from snake venoms. Non-covalently linked homodimer - haditoxin (Opiophagus hannah; Elapidae) and fulditoxin (Micrurus fulvius; Elapidae); Covalently linked heterodimer irditoxin (Boiga irregularis; Colubridae) $(2 \mathrm{H} 7 \mathrm{Z})$. The figures were generated using the respective PDB structures (accession number indicated in parenthesis) of each toxin. The species and family of the source are indicated. Disulfide bonds are shown in yellow.

\section{Conclusions, and clinical and scientific implications}

4.1 Aiding drug discovery by delineating the binding sites for positive allosteric modulators, noncompetitive antagonists and partial agonists in the nicotinic acetylcholine receptor

Drug discovery for Alzheimer's disease, schizophrenia and pain has turned to positive allosteric modulators of $n A C h R$ and $G_{A B A} R s$, as means to enhance endogenous neurotransmitter signalling while avoiding the prolonged, non-physiological pattern of receptor activation produced by agonists ${ }^{41-44,68,69}$. In this context, detailed structural data pertaining to the receptor of interest and its binding pockets for pharmacological modulation by positive allosteric modulators is critical for lead identification and optimisation. The identification of a novel lead (TDBzl-etomidate) $)^{9}$ and the detailed characterization of the positive allosteric modulator binding site in the nAChR ${ }^{12}$ has been regarded as a discovery of significance for therapies for neurodegenerative diseases (Forman $S$, Massachusetts General Hospital, Boston; Faculty of 1000 in Medicine, Post-Publication Expert Review). Likewise, detailed information about the binding sites for non-competitive antagonists and partial agonists within the nAChR, and by extrapolation $\mathrm{GABA}_{\mathrm{A}} \mathrm{R}$, provide valuable information for rational drug design.

\subsection{Scorpion toxins as therapeutic leads and molecular probes for potassium channel associated pathologies}

Given the role of voltage-gated $\mathrm{K}^{+}$channels in the pathophysiology of autoimmune disorders and cancer, and their potential as therapeutic targets ${ }^{48-50}$, knowledge of the structural and functional determinants by which scorpion toxins interact with $\mathrm{K}^{+}$channels will help develop therapies targeting $\mathrm{K}^{+}$channel dysfunction ${ }^{51,70}$. Our studies on Asian scorpion toxins (Heterometrus species) ${ }^{16-19}$ provide valuable information about the structural determinants of toxins for $\mathrm{K}^{+}$channel selectivity; and demonstrates that a cyclic mini-peptide, a fifth of the size of the native, toxin is able to replicate the pharmacological selectivity of the parent molecule for $\mathrm{K}+$ channels.

\subsection{Understanding molecular mechanisms underpinning snake envenomation syndromes}

The WHO has designated snakebite as a neglected tropical disease due to the significant morbidity and mortality following envenomation in Asia, Africa and Latin America ${ }^{71,72}$. Sri Lanka in particular, has one of the highest global incidence rates of venomous snakebites ${ }^{73-75}$. Globally, the venom composition and molecular actions of snake toxins of a majority of clinically relevant species have remained elusive ${ }^{76,77}$. Greater insight into the pharmacology of snake neurotoxins and their interactions with nAChRs provided by the discovery and characterization of new clades of snake toxins including dimeric neurotoxins will enhance our understanding of the molecular basis for their clinical envenoming syndromes, with potential for refining current management practices. 


\subsection{A novel snake neurotoxin as a molecular probe for labelling neuronal $\alpha 4 \beta 2$ nicotinic acetylcholine receptors implicated in neurodegenerative diseases}

To the best of our knowledge, fulditoxin is the only reported snake neurotoxin to produce potent $\left(\mathrm{IC}_{50} \sim 1.8 \mu \mathrm{M}\right)$ inhibition of neuronal $\alpha 4 \beta 2$ nAChRs implicated in the pathophysiology of pain, Alzheimer's and Parkinson's disease. Further elucidation of fulditoxin's structure-function relationships will offer a unique pharmacological probe to localise $\alpha 4 \beta 2 \mathrm{nAChRs}$ in histopathological analysis as well as a research tool for neurobiology and medicine.

\subsection{Application of a snake toxin-derived peptide in targeted drug delivery for brain tumours}

The blood-brain barrier poses a significant challenge in treating diseases of the central nervous system. In this context, the therapeutic efficacy of tumour necrosis factor-related apoptosis-inducing ligand (TRAIL) and paclitaxel (PTX) for the treatment of intracranial glioblastoma is suboptimal due to limitations in the penetration of the blood-brain barrier and blood-tumour barrier by drugs ${ }^{78}$. A 16-amino acid long peptide (CDX) was designed and developed from candoxin, a snake neurotoxin with high affinity $\left(\mathrm{IC}_{50}=50 \mathrm{nM}\right)$ for binding human neuronal $\alpha 7$ receptors 20,29 . CDX was conjugated with TRAIL and paclitaxel loaded micelles, and utilised as a brain-targeted drug delivery system capable of permeating the blood-brain barrier with great efficacy ${ }^{79,80}$. The anti-glioblastoma effects and in vivo bio-distribution observed with this targeted drug-delivery underscores the significant potential of $\mathrm{CDX}$ as brain-targeted drug delivery system.

\section{Acknowledgements}

I would like to gratefully recognize the mentorship and contributions of my collaborators Profs. M Kini, J Sivaraman, MCE Gwee, P Gopalakrishnakone (National University of Singapore); HE Khoo (Yale-NUS College, Singapore); JB Cohen (Harvard Medical School); D Bertrand (University of Geneva); PF Alewood (University of Queensland, Australia); DJ Adams (University of Wollongong, Australia); K Sato (Fukuoka Women's University, Japan); as well as doctoral students, Drs. CS Foo, A Roy, J Pawlak and V Hassan-Puttaswamy. The multiple research grants from the Biomedical Research Council of Singapore, National University of Singapore Academic Fund, National Neuroscience Institute of Singapore, SingHealth Foundation and Griffith Health Institute are also acknowledged.

This review is dedicated to the memory of Dr David Chiara MD PhD, Department of Neurobiology, Harvard Medical School, Boston, MA., USA; a key collaborator on work summarised in this paper, as well as an invaluable colleague, mentor and friend.

\section{References}

1. Verkman A. Drug discovery in academia. American Journal of Physiology-Cell Physiology 2004; 286(3): C465-C74.

2. Roy A. Early probe and drug discovery in academia: a minireview. High-Throughput 2018; 7(1): 4-18.

3. Clark RL, Johnston BF, Mackay SP, Breslin CJ, Robertson MN, Harvey AL. The Drug Discovery Portal: a resource to enhance drug discovery from academia. Drug Discovery Today 2010; 15(15-16): 679-83.

4. Amirkia V, Heinrich M. Natural products and drug discovery: A survey of stakeholders in industry and academia. Frontiers in Pharmacology 2015; 6: 237.

5. Peigneur S, Tytgat J. Toxins in drug discovery and pharmacology. Toxins 2018; 10(3): 126-30.

6. Lewis RJ, Garcia ML. Therapeutic potential of venom peptides. Nature Reviews: Drug Discovery 2003; 2(10): 790-802.

7. Harvey AL. Toxins and drug discovery. Toxicon 2014; 92: 193-200.

8. Middleton RE, Cohen JB. Mapping of the acetylcholine binding site of the nicotinic acetylcholine receptor: [3H]nicotine as an agonist photoaffinity label. Biochemistry 1991; 30(28): 6987-97.

9. Husain SS, Nirthanan S, Ruesch D, Solt K, Cheng Q, Li GD, Arevalo E, Olsen RW, Raines DE, Forman SA, Cohen JB, Miller KW. Synthesis of trifluoromethylaryl diazirine and benzophenone derivatives of etomidate that are potent general anesthetics and effective photolabels for probing sites on ligand-gated ion channels. Journal of Medicinal Chemistry 2006; 49(16): 4818-25. 
10. Ziebell MR, Nirthanan S, Husain SS, Miller KW, Cohen JB. Identification of binding sites in the nicotinic acetylcholine receptor for [3H]azietomidate, a photoactivatable general anesthetic. Journal of Biological Chemistry 2004; 279(17): 17640-49.

11. Nirthanan S, Ziebell MR, Chiara DC, Hong F, Cohen JB. Photolabeling the Torpedo nicotinic acetylcholine receptor with 4-azido2,3,5,6-tetrafluorobenzoylcholine, a partial agonist. Biochemistry 2005; 44(41): 13447-56.

12. Nirthanan S, Garcia G, 3rd, Chiara DC, Husain SS, Cohen JB. Identification of binding sites in the nicotinic acetylcholine receptor for TDBzl-etomidate, a photoreactive positive allosteric effector. Journal of Biological Chemistry 2008; 283(32): 22051-62.

13. Andreeva IE, Nirthanan S, Cohen JB, Pedersen SE. Site specificity of agonist-induced opening and desensitization of the Torpedo californica nicotinic acetylcholine receptor. Biochemistry 2006; 45(1): 195-204.

14. Garcia G, 3rd, Chiara DC, Nirthanan S, Hamouda AK, Stewart DS, Cohen JB. [3H]Benzophenone photolabeling identifies statedependent changes in nicotinic acetylcholine receptor structure. Biochemistry 2007; 46(36): 10296-307.

15. Nirthanan S, Joseph JS, Gopalakrishnakone P, Khoo H-E, Cheah L-S, Gwee MC. Biochemical and pharmacological characterization of the venom of the black scorpion Heterometrus spinifer. Biochemical Pharmacology 2002; 63(1): 49-55.

16. Nirthanan S, Pil J, Abdel-Mottaleb Y, Sugahara Y, Gopalakrishnakone P, Joseph JS, Sato K, Tytgat J. Assignment of voltage-gated potassium channel blocking activity to $\mathrm{KKTx} 1.3$, a non-toxic homologue of $\kappa$-hefutoxin-1, from Heterometrus spinifer venom. Biochemical Pharmacology 2005; 69(4): 669-78.

17. Srinivasan K, Nirthanan S, Sasaki T, Sato K, Cheng B, Gwee M, Kini R, Gopalakrishnakone P. Functional site of bukatoxin, an $\alpha$-type sodium channel neurotoxin from the Chinese scorpion (Buthus martensi Karsch) venom: probable role of the ${ }^{52}$ PDKVP ${ }^{56}$ loop. FEBS Letters 2001; 494(3): 145-9.

18. Peigneur S, Yamaguchi Y, Kawano C, Nose T, Nirthanan S, Gopalakrishnakone P, Tytgat J, Sato K. Active sites of spinoxin, a potassium channel scorpion toxin, elucidated by systematic alanine scanning. Biochemistry 2016; 55(21): 2927-35.

19. Yamaguchi Y, Peigneur S, Liu JY, Uemura S, Nose T, Nirthanan S, Gopalakrishnakone P, Tytgat J, Sato K. Role of individual disulfide bridges in the conformation and activity of spinoxin (a-KTx6.13), a potassium channel toxin from Heterometrus spinifer scorpion venom. Toxicon 2016; 122: 31-38.

20. Nirthanan S, Charpantier E, Gopalakrishnakone P, Gwee MC-E, Khoo H-E, Cheah L-S, Bertrand D, Kini RM. Candoxin, a novel toxin from Bungarus candidus, is a reversible antagonist of muscle $(\alpha \beta \gamma \delta)$ but a poorly reversible antagonist of neuronal $\alpha 7$ nicotinic acetylcholine receptors. Journal of Biological Chemistry 2002; 277(20): 17811-20.

21. Nirthanan S, Gao R, Gopalakrishnakone P, Gwee M, Khoo H, Cheah L, Kini RM. Pharmacological characterization of mikatoxin, an $\alpha$-neurotoxin isolated from the venom of the New-Guinean small-eyed snake Micropechis ikaheka. Toxicon 2002; 40(7): 863-71.

22. Pawlak J, Mackessy SP, Sixberry NM, Stura EA, Le Du MH, Ménez R, Foo CS, MénezA, Nirthanan S, Kini RM. Irditoxin, a novel covalently linked heterodimeric three-finger toxin with high taxon-specific neurotoxicity. FASEB Journal 2009; 23(2): 534-45.

23. Roy A, Zhou X, Chong MZ, D'Hoedt D, Foo CS, Rajagopalan N, Nirthanan S, Bertrand D, Sivaraman J, Kini RM. Structural and functional characterization of a novel homodimeric three-finger neurotoxin from the venom of Ophiophagus hannah (king cobra). Journal of Biological Chemistry 2010; 285(11): 8302-15.

24. Paaventhan P, Joseph JS, Nirthanan S, Rajaseger G, Gopalakrishnakone P, Kini MR, Kolatkar PR. Crystallization and preliminary Xray analysis of candoxin, a novel reversible neurotoxin from the Malayan krait Bungarus candidus. Acta Crystallographica Section D: Biological Crystallography 2003; 59(3): 584-6.

25. Watanabe L, Nirthanan S, Rajaseger G, Polikarpov I, Kini R, Arni R. Crystallization and preliminary X-ray analysis of bucain, a novel toxin from the Malayan krait Bungarus candidus. Acta Crystallographica Section D: Biological Crystallography 2002; 58(10): 1879-81.

26. Torres AM, Kini RM, Nirthanan S, Kuchel PW. NMR structure of bucandin, a neurotoxin from the venom of the Malayan krait (Bungarus candidus). Biochemical Journal 2001; 360(3): 539-48.

27. Rani Parvathy V, Charya KV, Kini RM, Govila G. Solution structure of candoxin, a novel three-finger toxin from the venom of Bungarus candidus. ARKIVOC: Free Online Journal of Organic Chemistry 2006; 15: 1-16.

28. Cheah LS, Gwee MC, Nirthanan S. Characterization of the rat isolated retractor penis muscle as a model for the study of nitrergic transmission. Journal of Pharmacological and Toxicological Methods 2002; 47(2): 79-85.

29. Nirthanan S, Charpantier E, Gopalakrishnakone P, Gwee M, Khoo H, Cheah L, Kini RM, Bertrand D. Neuromuscular effects of candoxin, a novel toxin from the venom of the Malayan krait (Bungarus candidus). British Journal of Pharmacology 2003; 139(4): 832-44. 
30. Ginsborg BL, Warriner J. The isolated chick biventer cervicis nerve-muscle preparation. British Journal of Pharmacology and Chemotherapy 1960; 15: 410-11.

31. Bulbring E. Observations on the isolated phrenic nerve diaphragm preparation of the rat. British Journal of Pharmacology and Chemotherapy 1946; 1: 38-61.

32. International Guiding Principles for Biomedical Research Involving Animals issued by CIOMS. Veterinary Quarterly 1986; 8(4): 350-52.

33. Hurst R, Rollema H, Bertrand D. Nicotinic acetylcholine receptors: from basic science to therapeutics. Pharmacology and Therapeutics 2013; 137(1): 22-54.

34. D'Hoedt D, Bertrand D. Nicotinic acetylcholine receptors: an overview on drug discovery. Expert Opinion on Therapeutic Targets 2009; 13(4): 395-411.

35. Sigel E, Steinmann ME. Structure, function, and modulation of $\left.\mathrm{GABA}_{A}\right)$ receptors. Journal of Biological Chemistry 2012; 287(48): 40224-31.

36. Masiulis S, Desai R, Uchanski T, Martin IS, Laverty D, Karia D, Malinauskas T, Zivanov J, Pardon E, KotechaA, Steyaert J, Miller KW, Aricescu AR. GABA $\left({ }_{A}\right)$ receptor signalling mechanisms revealed by structural pharmacology. Nature 2019; 565(7740): 454-+.

37. Dineley KT, Pandya AA, Yakel JL. Nicotinic ACh receptors as therapeutic targets in CNS disorders. Trends in Pharmacological Sciences 2015; 36(2): 96-108.

38. Unwin N. Refined structure of the nicotinic acetylcholine receptor at 4A resolution. Journal of Molecular Biology 2005; 346(4): 967-89.

39. Laverty D, Desai R, Uchanski T, Masiulis S, Stec WJ, Malinauskas T, Zivanov J, Pardon E, Steyaert J, Miller KW, Aricescu AR. CryoEM structure of the human a1 b3 g2 GABA $\left._{A}\right)$ receptor in a lipid bilayer. Nature 2019; 565(7740): 516-20.

40. Cecchini M, Changeux JP. The nicotinic acetylcholine receptor and its prokaryotic homologues: Structure, conformational transitions and allosteric modulation. Neuropharmacology 2015; 96(Pt B): 137-49.

41. Soh MS, Lynch JW. Selective modulators of a(5)-containing $\left.\operatorname{GABA}_{A}\right)$ receptors and their therapeutic significance. Current Drug Targets 2015; 16(7): 735-46.

42. Echeverria V, Yarkov A, Aliev G. Positive modulators of the a7 nicotinic receptor against neuroinflammation and cognitive impairment in Alzheimer's disease. Progress in Neurobiology 2016; 144: 142-57.

43. Manetti D, Bellucci C, Chiaramonte N, Dei S, Teodori E, Romanelli MN. Designing selective modulators for the nicotinic receptor subtypes: challenges and opportunities. Future Medicinal Chemistry 2018; 10(4): 433-60.

44. Uteshev VV. Allosteric modulation of nicotinic acetylcholine receptors: The concept and therapeutic trends. Current Pharmaceutical Design 2016; 22(14): 1986-97.

45. Cahill K, Lindson-Hawley N, Thomas KH, Fanshawe TR, Lancaster T. Nicotine receptor partial agonists for smoking cessation. Cochrane Database of Systematic Reviews 2016; (5).

46. Buccafusco JJ, Letchworth SR, Bencherif M, Lippiello PM. Long-lasting cognitive improvement with nicotinic receptor agonists: mechanisms of pharmacokinetic-pharmacodynamic discordance. Trends in Pharmacological Sciences 2005; 26(7): 352-60.

47. Jenkinson DH. Potassium channels - multiplicity and challenges. British Journal of Pharmacology 2006; 147 Suppl 1: S63-71.

48. Wulff H, Castle NA, Pardo LA. Voltage-gated potassium channels as therapeutic targets. Nature Reviews: Drug Discovery 2009; 8(12): 982-1001.

49. Beeton C, Wulff H, Standifer NE, Azam P, Mullen KM, Pennington MW, Kolski-Andreaco A, Wei E, Grino A, Counts DR, Wang PH, LeeHealey CJ, B SA, Sankaranarayanan A, Homerick D, Roeck WW, Tehranzadeh J, Stanhope KL, Zimin P, Havel PJ, Griffey S, Knaus HG, Nepom GT, Gutman GA, Calabresi PA, Chandy KG. Kv1.3 channels are a therapeutic target for T cell-mediated autoimmune diseases. Proceedings of the National Academy of Sciences of the United States of America. 2006;103(46): 17414-19.

50. Teisseyre A, Gasiorowska J, Michalak K. Voltage-gated potassium channels Kv1.3 - Potentially new molecular target in cancer diagnostics and therapy. Adv Clin Exp Med. 2015; 24(3): 517-24.

51. Rodriguez de la Vega RC, Merino E, Becerril B, Possani LD. Novel interactions between $\mathrm{K}^{+}$channels and scorpion toxins. Trends in Pharmacological Sciences. 2003; 24(5): 222-7.

52. Ortiz E, Gurrola GB, Schwartz EF, Possani LD. Scorpion venom components as potential candidates for drug development. Toxicon 2015; 93:125-35. 
53. Tytgat J, Chandy KG, Garcia ML, Gutman GA, Martin-Eauclaire MF, van der Walt JJ, Possani LD. A unified nomenclature for shortchain peptides isolated from scorpion venoms: alpha-KTx molecular subfamilies. Trends in Pharmacological Sciences 1999; 20(11): 444-47.

54. Yuan SL, Gao B, Zhu SY. Molecular dynamics simulation reveals specific interaction sites between scorpion toxins and K(v)1.2 channel: Implications for design of highly selective drugs. Toxins 2017; 9(11): 354-73.

55. Srinivasan KN, Sivaraja V, Huys I, Sasaki T, Cheng B, Kumar TK, Sato K, Tytgat J, Yu C, San BC, Ranganathan S, Bowie HJ, Kini RM, Gopalakrishnakone P. k-Hefutoxin1, a novel toxin from the scorpion Heterometrus fulvipes with unique structure and function. Importance of the functional diad in potassium channel selectivity. Journal of Biological Chemistry 2002; 277(33): 30040-7.

56. Peigneur S, Yamaguchi Y, Goto H, Srinivasan KN, Gopalakrishnakone P, Tytgat J, Sato K. Synthesis and characterization of amino acid deletion analogs of k-hefutoxin 1, a scorpion toxin on potassium channels. Toxicon 2013; 71: 25-30.

57. Mouhat S, Mosbah A, Visan V, Wulff H, Delepierre M, Darbon H, Grissmer S, De Waard M, Sabatier JM. The 'functional' dyad of scorpion toxin $\mathrm{Pi} 1$ is not itself a prerequisite for toxin binding to the voltage-gated Kv1.2 potassium channels. Biochemical Journal 2004; 377(Pt 1): 25-36.

58. Sugahara Y, Nirthanan S, Huys I, Kobayashi K, Kohno T, Tytgat J, Gopalakrishnakone P, Sato K. Synthesis and characterization of spinoxin, a novel peptide toxin from the Malaysian black scorpion. Peptide Science-Proceedings of the 40th Symposium on Japanese Peptide Symposium. 2004: 283-4.

59. Changeux JP. The nicotinic acetylcholine receptor: the founding father of the pentameric ligand-gated ion channel superfamily. Journal of Biological Chemistry 2012; 287(48): 40207-15.

60. Nirthanan S, Awal W, Niranjan N. Snake $\alpha$-neurotoxins and the nicotinic acetylcholine receptor. In: Gopalakrishnakone P, Inagaki H, Mukherjee AK, Rahmy TR, Vogel C-W, editors. Snake Venoms. Dordrecht: Springer Netherlands; 2017: 215-52.

61. Nirthanan S, Gwee MCE. Three-finger $\alpha$-neurotoxins and the nicotinic acetylcholine receptor, forty years on. Journal of Pharmacological Sciences 2004; 94(1): 1-17.

62. McIntosh JM, Absalom N, Chebib M, Elgoyhen AB, Vincler M. a9 Nicotinic acetylcholine receptors and the treatment of pain. Biochemical Pharmacology 2009; 78(7): 693-702.

63. Nirthanan S, Gopalakrishnakone P, Gwee MC, Khoo HE, Kini RM. Non-conventional toxins from Elapid venoms. Toxicon 2003; 41(4): 397-407.

64. Buccafusco JJ. Neuronal nicotinic receptor subtypes: defining therapeutic targets. Molecular Interventions 2004; 4(5): $285-95$.

65. Chiappinelli VA, Weaver WR, McLane KE, Conti-Fine BM, Fiordalisi JJ, Grant GA. Binding of native k-neurotoxins and site-directed mutants to nicotinic acetylcholine receptors. Toxicon 1996; 34(11-12): 1243-56.

66. Foo CS, Nirthanan S, Kini R, Wong PT. Biochemical and pharmacological characterization of three-finger neurotoxins from the venom of Eastern coral snake (Micrurus fulvius fulvius). Toxicon 2012; 2(60): 173.

67. Servent D, Winckler-Dietrich V, Hu HY, Kessler P, Drevet P, Bertrand D, Menez A. Only snake curaremimetic toxins with a fifth disulfide bond have high affinity for the neuronal a7 nicotinic receptor. Journal of Biological Chemistry 1997; 272(39): $24279-86$.

68. McCarson KE, Enna SJ. GABA Pharmacology: The Search for Analgesics. Neurochemical Research 2014; 39(10): $1948-63$.

69. Taly A, Corringer PJ, Guedin D, Lestage P, Changeux JP. Nicotinic receptors: allosteric transitions and therapeutic targets in the nervous system. Nature Reviews. Drug Discovery 2009; 8(9): 733-50.

70. BartokA, Panyi G, Varga Z. Potassium Channel-Blocking Peptide Toxins from Scorpion Venom. In: Gopalakrishnakone P, Ferroni Schwartz E, Possani LD, Rodríguez de la Vega RC, editors. Scorpion Venoms: Springer Netherlands 2015: 493-527.

71. Williams D, Gutierrez JM, Harrison R, Warrell DA, White J, Winkel KD, Gopalakrishnakone P. The Global Snake Bite Initiative: an antidote for snake bite. Lancet 2010; 375(9708): 89-91.

72. Gutierrez JM, Williams D, Fan HW, Warrell DA. Snakebite envenoming from a global perspective: Towards an integrated approach. Toxicon 2010; 56(7): 1223-35.

73. Kasturiratne A, Pathmeswaran A, Fonseka MM, Lalloo DG, Brooker S, de Silva HJ. Estimates of disease burden due to land-snake bite in Sri Lankan hospitals. Southeast Asian Journal of Tropical Medicine and Public Health 2005; 36(3): 733-40.

74. Bell DJ, Wijegunasinghe D, Samarakoon S, Palipana H, Gunasekera S, de Silva HA, Lalloo DG, Ranawaka UK, de Silva HJ. Neurophysiological findings in patients one year after snake bite induced neurotoxicity in Sri Lanka. Transactions of the Royal Society of Tropical Medicine and Hygiene 2010; 104(5): 351-56. 
75. Seneviratne SL, Opanayaka CJ, Ratnayake NS, Kumara KE, Sugathadasa AM, Weerasuriya N, Wickrama WA, Gunatilake SB, de Silva HJ. Use of antivenom serum in snake bite: a prospective study of hospital practice in the Gampaha district. Ceylon Medical Journal 2000; 45(2): 65-8.

76. St Pierre L, Fischer H, Adams DJ, Schenning M, Lavidis N, de Jersey J, Masci PP, Lavin MF. Distinct activities of novel neurotoxins from Australian venomous snakes for nicotinic acetylcholine receptors. Cellular and Molecular Life Sciences 2007; 64(21): 282940.

77. Birrell GW, Earl ST, Wallis TP, Masci PP, de Jersey J, Gorman JJ, Lavin MF. The diversity of bioactive proteins in Australian snake venoms. Molecular \& Cellular Proteomics 2007; 6(6): 973-986.

78. Zhan C, Wei X, Qian J, Feng L, Zhu J, Lu W. Co-delivery of TRAIL gene enhances the anti-glioblastoma effect of paclitaxel in vitro and in vivo. Journal of Controlled Release. 2012; 160(3): 630-6.

79. Zhan C, Li B, Hu L, Wei X, Feng L, Fu W, Lu W. Micelle-based brain-targeted drug delivery enabled by a nicotine acetylcholine receptor ligand. Angewandte Chemie International Ed In English 2011; 50(24): 5482-5.

80. Zhan C, Lu W. The blood-brain/tumor barriers: challenges and chances for malignant gliomas targeted drug delivery. Current Pharmaceutical Biotechnology 2012; 13(12): 2380-7. 